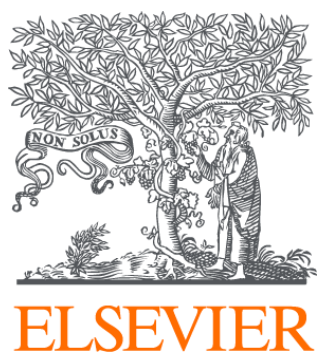

Since January 2020 Elsevier has created a COVID-19 resource centre with free information in English and Mandarin on the novel coronavirus COVID-

19. The COVID-19 resource centre is hosted on Elsevier Connect, the company's public news and information website.

Elsevier hereby grants permission to make all its COVID-19-related research that is available on the COVID-19 resource centre - including this research content - immediately available in PubMed Central and other publicly funded repositories, such as the WHO COVID database with rights for unrestricted research re-use and analyses in any form or by any means with acknowledgement of the original source. These permissions are granted for free by Elsevier for as long as the COVID-19 resource centre remains active. 


\title{
Evaluation of the filtration performance of 2 I N95 filtering face piece respirators after prolonged storage
}

Dennis J. Viscusi, BS, ${ }^{\mathrm{a}}$ Mike Bergman, $\mathrm{MS},{ }^{\mathrm{b}}$ Edward Sinkule, MS, ${ }^{\mathrm{a}}$ and Ronald E. Shaffer, $\mathrm{PhD}^{\mathrm{a}}$ Pittsburgh, Pennsylvania

\begin{abstract}
Background: Organizations are stockpiling respirators to prepare for an influenza pandemic. To understand better the effects of prolonged storage, this investigation evaluated the filtration efficiency of 21 different models of National Institute for Occupational Safety and Health (NIOSH)-certified disposable N95 filtering face piece respirators. These respirators had been stored in their original packaging for a period of at least 6 years in research laboratories and dry warehouse facilities, ranging in temperature between $15^{\circ} \mathrm{C}$ and $32^{\circ} \mathrm{C}$ and relative humidity between $20 \%$ and $80 \%$

Methods: Filter penetration was measured using an abbreviated version of the NIOSH respirator certification test incorporating a polydisperse sodium chloride aerosol at $85 \mathrm{~L} / \mathrm{min}$.

Results: Of the 21 respirator models tested, 19 models had both average penetration results of less than $5 \%$. Mean initial penetration values ranged from $0.39 \%$ to $5.83 \%$, whereas mean maximum penetration values ranged from $0.95 \%$ to $5.83 \%$. There did not appear to be any correlation between the length of storage and failure to pass the filtration test.

Conclusion: Results indicate that most N95 filtering face piece respirators stored for up to 10 years at warehouse conditions will likely have expected levels of filtration performance and that the degree of filtration efficiency degradation is likely model specific.

Copyright (c) 2009 by the Association for Professionals in Infection Control and Epidemiology, Inc.

(Am J Infect Control 2009;37:381-6.)
\end{abstract}

Growing concern over a possible shortage of disposable N95 filtering face piece respirators (N95FFRs) in the event of widespread outbreak of airborne transmitted infectious disease has drawn the attention of health care workers (HCW) and local, state, and federal public health officials. Current guidance for treating patients with an infectious disease involves frequently discarding N95FFRs, resulting in rapid depletion of existing supplies. To address this concern, the Department of Health and Human Services (DHHS) asked the Institute of Medicine (IOM) to conduct an analysis of the potential reuse of disposable N95FFR and N95 respirator/surgical

From the National Institute for Occupational Safety and Health, National Personal Protective Technology Laboratory ${ }^{\mathrm{a}}$ and EG\&G Technical Services, Inc, ${ }^{\text {b }}$ Pittsburgh, PA.

Address correspondence to Ronald E. Shaffer, PhD, Chief, Technology Research Branch, National Personal Protective Technology Lab (NPPTL), National Institute for Occupational Safety and Health (NIOSH), Centers for Disease Control and Prevention (CDC), 626 Cochrans Mill Road, Building 29, P.O. Box 18070, Pittsburgh, PA 15236. E-mail: RShaffer@cdc.gov.

The findings and conclusions in this report are those of the authors and do not necessarily represent the views of the National Institute for Occupational Safety and Health (NIOSH). Mention of company names or products does not constitute endorsement by NIOSH.

Conflicts of interest: None to report.

0196-6553/\$36.00

Copyright (C) 2009 by the Association for Professionals in Infection Control and Epidemiology, Inc.

doi:10.1016/j.ajic.2008.09.021 masks. During this analysis, the IOM found that the demand for $\mathrm{N} 95$ respirators by the health care sector alone could be over 90 million for a 42-day influenza pandemic outbreak. ${ }^{1}$ This analysis was consistent with the observation at Sunnybrook Hospital in Toronto, Canada, where 18,000 N95FFRs were used daily during the 2003 severe acute respiratory syndrome outbreak. ${ }^{2}$ Current respirator manufacturing techniques and practices make it difficult to increase production to meet unexpected demand. In the case of a global event, it may be difficult to transport resources to the location with the greatest need. Thus, there is an overarching need for solutions to a probable shortage of N95FFRs.

Two potential solutions have been identified to possibly abate this demand: (1) reuse (via FFR decontamination or surgical mask overlay) and (2) stockpiling. There are advantages and disadvantages to both choices; however, stockpiling is preferred by many because of the uncertainty associated with potential reuse of an N95FFR. The government of France began stockpiling 685 million N95FFRs for its HCWs. ${ }^{3}$ The US Strategic National Stockpile currently includes 100 million N95FFRs for distribution mainly to HCWs in the event of a national emergency. ${ }^{4}$

One concern with stockpiling N95FFRs is whether prolonged storage affects filtration performance. The National Institute for Occupation Safety and Health (NIOSH) requires filter testing as part of the respirator certification process. Most N95FFRs sold commercially in the last decade use electret filter media. Electret or electrostatic filter media are produced by imparting a 
static electric charge on split polypropylene fibers to enhance their capture efficiency via coulombic attraction and polarizing forces. ${ }^{5}$ Electret filter media are designed to improve the filter collection efficiency of submicrometer particles, without an increase in breathing resistance (pressure drop). Respirators utilizing electret filter media can generally be made lighter in weight and more compact than those composed of purely mechanical filter media. ${ }^{6}$ A drawback to electret filter media is that, if the electrostatic charge is lost or removed, filtration efficiency for submicrometer particles degrades significantly. However, significantly degraded electret media can still achieve excellent filtration performance when tested against common workplace aerosols, which are nearly always larger than the aerosol size range used in the NIOSH certification test. ${ }^{7}$

Certain chemical and physical processes are known to degrade the laboratory filtration performance of N95FFRs employing electret filter media. The degradation of electret filter media using organic solvents has been widely reported in the literature. ${ }^{8-11}$ In general, studies have shown that organic solvents (eg, ethanol and isopropyl alcohol) when applied in liquid form cause significant change to the laboratory filtration performance of respirators containing electret filter media. ${ }^{12,13}$ Likewise, physical processes including gamma radiation, ${ }^{14}$ heat, ${ }^{11}$ and $\mathrm{x}$-ray radiation ${ }^{14,15}$ are known to degrade electret filter media. However, other chemical and physical processes such as simulated decontamination using tap water, ultraviolet radiation, or hydrogen peroxide (vaporized and liquid forms) caused no statistically significant change to electret filter performance. ${ }^{11}$ Moreover, other studies have found that dipping N95FFRs in water for 15 seconds had only a minimal effect on filtration performance. ${ }^{12}$ Although Ackley ${ }^{16}$ has characterized the degradation of electrostatic media at elevated temperatures (up to $65^{\circ} \mathrm{C}$ ) and humidity (up to $90 \%$ relative humidity), the effects of these extreme conditions have only been studied for relatively short durations of time.

Early studies of electret filters have reported life expectancies (retained their electrostatic charge and capture efficiencies) of over a year, even at high temperatures and humidity levels. ${ }^{17,18}$ In another more recent study of nonwoven polypropylene electret filter media, the effect of relative humidity on charge decay and lifetime was reported by Motyl and Lowkis. ${ }^{19}$ Those authors found that conditioning samples at higher humidity influences the lifetime of the electret fiber. For the 2 polypropylene filters studied, lifetimes between 1 year and 2.3 years were predicted based on models developed using thermally stimulated equivalent surface voltage data. However, the effect of longer storage time (several years or more) on commercially available FFRs has not been reported in the literature.
The Occupational Safety and Health Administration (OSHA) Respiratory Protection Standard specifies in 29 CFR 1910.134(h)(2)(i) that respirators must be stored to protect them against physical damage, contamination, dust, extreme temperatures, excessive moisture, sunlight, and damaging chemicals. ${ }^{20}$ However, the OSHA standard does not specify a requirement for storage duration (ie, a maximum shelf life). Currently, there is no stated shelf life or use-before-date for NIOSH-approved FFRs provided they are stored undamaged in their original packaging at normal room temperature $\left(15^{\circ} \mathrm{C}\right.$ to $27^{\circ} \mathrm{C}$ ). Manufacturers may provide users with specific shelf-life guidance on their products, and some manufacturers offer expiration dates, which are also based on time testing. One manufacturer provided information to its customers that they currently test respirator performance after storage for up to 3 years (Letter from 3M Occupational Health and Safety Division, 2006). They further added, "Internal testing results show respirators stored in their original packaging (as if for sale) at normal room temperature $\left(15^{\circ} \mathrm{C}\right.$ to $\left.27^{\circ} \mathrm{C}\right)$ still meet NIOSH 42 CFR 84 performance specifications after 3 years of storage."

Because stockpiling is a recent phenomenon (most workplaces use just-in-time inventory and keep only as many as they need on hand), the effect of prolonged storage on filtration performance of N95FFRs has not raised much attention. The goal of this article is to report the filtration performance of commercially available N95FFRs stored for 6 to 10 years to determine whether there was a significant change in their filtration characteristics as well as to discuss the implications of these results for N95FFR stockpile administrators. This information will also be useful for policy makers in public health, infection control, and pandemic planning until a more formal aging study can be completed.

\section{METHODS}

\section{Respirators}

Twenty-one different models of N95 particulate filtering face piece respirators were purchased for use in previous NIOSH respirator research projects. These respirators were randomly selected from the pool of commercially available respirators at the time of those studies. Unused respirators from these projects were stored together for at least 6 years in dry warehouse facilities or for short periods of time in research laboratories (to account for the short time periods that the FFRs were not being stored in the warehouse facilities), ranging in temperature between $15^{\circ} \mathrm{C}$ and $32^{\circ} \mathrm{C}$ and relative humidity between $20 \%$ and $80 \%$. The warehouse was heated but not air-conditioned. All respirators were stored in the original packaging and within cardboard boxes used for shipment. Purchase records were used 
to determine the purchase dates. If purchase records were not available, the purchase date was determined by the date of the NIOSH project. If the size of the respirator was not available from the purchase records, respirator packaging, or respirator labeling, it was labeled as "one-size-fits-all." Table 1 provides the characteristics of the respirators, dates stamped on the original packaging, and the approximate dates of purchase.

\section{Equipment}

A TSI Model 8130 Automated Filter Tester (AFT) (TSI, Inc., St. Paul, MN) was used to a measure filter resistance (pressure drop in $\mathrm{mm}_{2} \mathrm{O}$ column height pressure) and percent filter penetration. The TSI 8130 AFT delivers a solid polydisperse sodium chloride $(\mathrm{NaCl})$ aerosol that meets the particle size distribution criteria set forth in 42 CFR 84 Subpart K, Section 84.181 for NIOSH certification. ${ }^{21}$ Filter resistance is measured using a combination of a flowmeter and 2 electronic pressure transducers that measure the pressure drop through the filter or filter media under test. The AFT uses a metal tube with an internal orifice. The flow passes upward through the flowmeter, and the pressure difference across the orifice is measured with the pressure transducers. The pressure difference is converted to flowrate using a calibration data curve.

The $\mathrm{NaCl}$ aerosol has a count median diameter of $0.075 \pm 0.020 \mu \mathrm{m}$ and a geometric standard deviation not exceeding 1.86 and was charge neutralized to the Boltzmann equilibrium state. The TSI 8130 uses a photometer to measure the flux of light scattering from aerosol particles. This method is based on the fact that the flux of scattered light is proportional to mass squared or particle diameter raised to the sixth power when the diameter is smaller than the wavelength of the coincident light. ${ }^{22}$ All polydisperse aerosol tests were conducted at room temperature with a continuous airflow of $85 \pm 2 \mathrm{~L} / \mathrm{min}$ in accordance with all of the NIOSH certification criteria for challenging $\mathrm{N}$-series filters. ${ }^{21,23}$

Particle penetration through the N95FFR was determined using a cubic Plexiglas box $\left(20 \times 20 \times 10 \mathrm{~cm}^{3}\right)$ placed between the filter chucks (sample holding flange mechanism on the AFT). The top and bottom removable $3.2-\mathrm{mm}$ aluminum plates $(20 \times 20 \mathrm{~cm})$ of the Plexiglas box had a circular hole $\left(25 \mathrm{~cm}^{2}\right)$ in the center of each plate. The N95FFR was placed on the bottom plate with its concave side facing the hole. The periphery of the N95FFR was sealed to the bottom plate with melted beeswax. The bottom plate with the N95FFR was placed under the Plexiglas box just above the downstream side of the filter holder so that the convex side of the N95FFR was facing the aerosol upstream side of the filter holder followed by the addition of the top plate. The Plexiglas box containing the N95FFR was then placed between the 2 chucks of the filter holder and aligned vertically to keep the holes of the Plexiglas box centered with respect to the filter chucks. Airtight sealing was maintained using continuous and precisely cut gasket material between the plates and the box, a minimum of vacuum grease

Table I. Description of N95FFRs

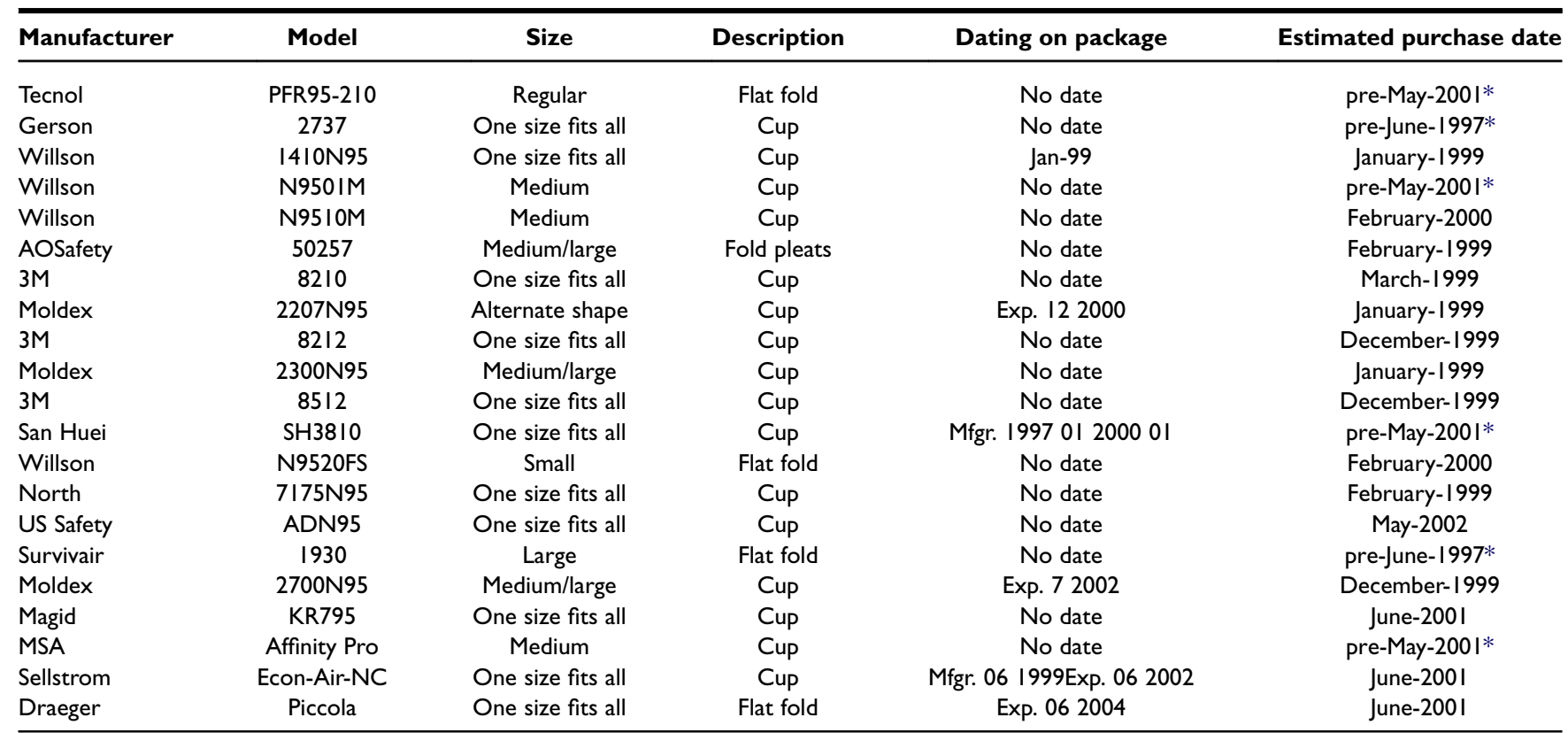

*Purchase date based on the NIOSH project when purchase records were not available. 
(lubricant and pore filler), and the pressure created by closing the filter chucks.

\section{Data collection procedures}

Sixty-three N95FFRs from 21 different models were tested to measure percent filter penetration and filter resistance using the TSI 8130 AFT. Prior to filtration efficiency testing, all N95FFR samples were environmentally preconditioned in accordance with the requirements of the NIOSH 42 CFR 84 particulate respirator certification protocol; samples were taken out of their original packaging and placed in a preconditioning chamber at $85 \% \pm 5 \%$ relative humidity and $38^{\circ} \mathrm{C} \pm 2.5^{\circ} \mathrm{C}$ for $25 \pm 1$ hours. ${ }^{21,23}$

Polydisperse $\mathrm{NaCl}$ aerosol loading tests were performed with the TSI 8130 AFT until it was determined that a maximum penetration value was obtained. This test typically takes approximately 90 to 100 minutes to load $200 \mathrm{mg}$ of $\mathrm{NaCl}$ aerosol onto the respirator. The initial penetration value (which is measured at approximately the first minute of the loading test), the maximum penetration value, and the filter resistance of the N95FFR were recorded. Three replicate N95FFR samples from each of the 21 models were tested by this procedure. Data collection was conducted June 2007 through December 2007. The filter test methods used in this study differ slightly from the methods used in NIOSH certification and audit testing. Three samples per model were tested instead of 20 , as is required by 42 CFR $84.181 .^{21}$ In addition, the reported resistance values were obtained from the TSI 8130 AFT. These values should not be considered identical to inhalation resistance values obtained during NIOSH certification testing because those inhalation measurements are performed on separate calibrated test equipment. ${ }^{21}$

\section{Statistical analysis}

For each of the 21 respirator models tested ( $n=3$ for each model), the mean and standard deviation were calculated using Microsoft Excel software (Microsoft Corp, Redmond, WA) for the following parameters: (1) filter resistance at maximum penetration $\left(\mathrm{mm} \mathrm{H}_{2} \mathrm{O}\right)$, (2) initial penetration (\%), and (3) maximum penetration (\%). To analyze the penetrations after prolonged storage, we categorized each of the 21 average penetration values as either passing or failing versus the targeted $5 \% \mathrm{NIOSH}$ certification maximum allowable penetration level. ${ }^{21}$

\section{RESULTS}

Filter penetration and resistance results are presented in Table 2. Mean initial penetration values ranged from $0.39 \%$ to $5.83 \%$, and mean maximum

Table 2. TSI 8I30 AFT means and standard deviations for resistance and penetration for 21 N95FFRs following prolonged storage*

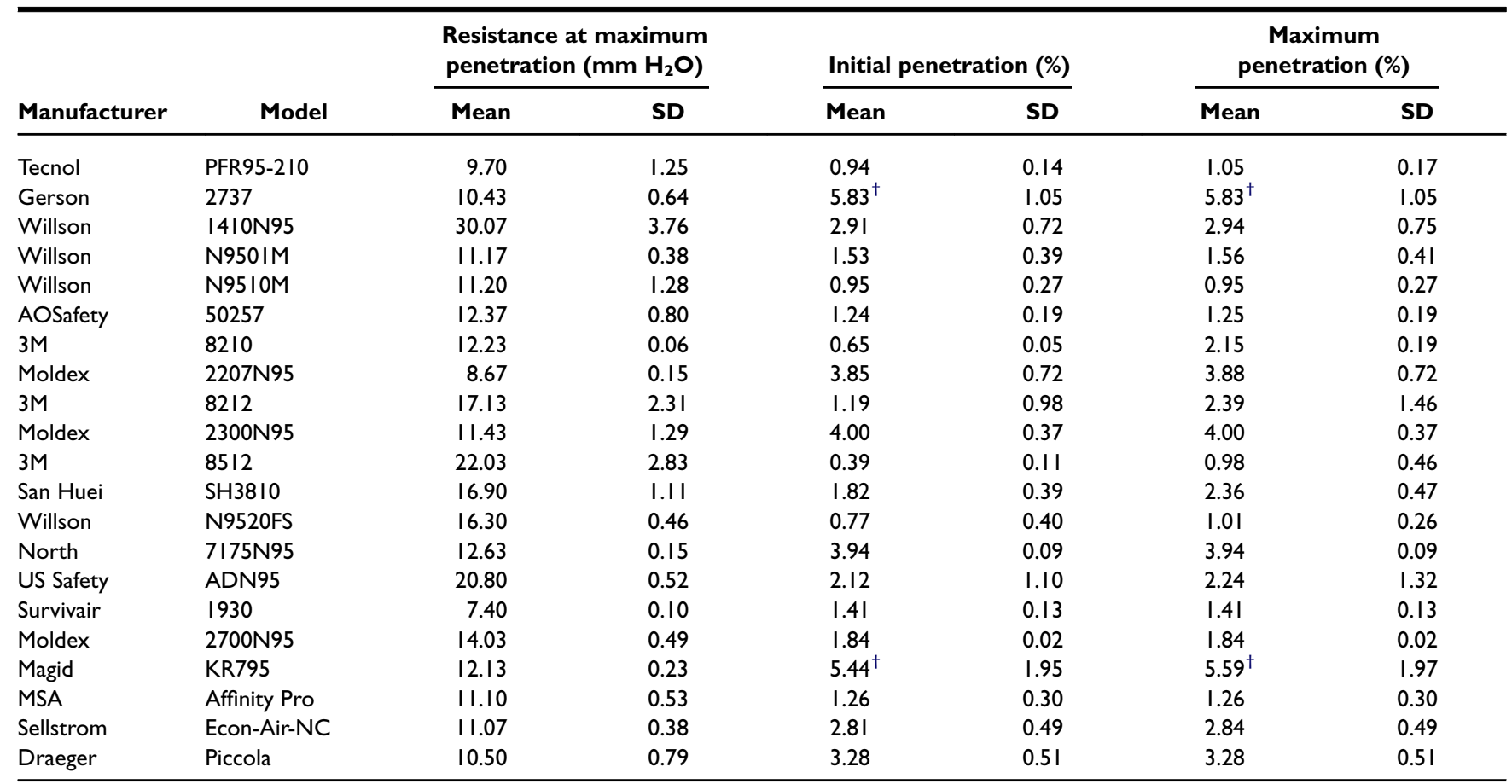

SD, standard deviation.

*N95 respirators were loaded with $\mathrm{NaCl}$ aerosol until their maximum penetration was observed.

${ }^{\dagger}$ Values exceed the $5 \%$ NIOSH certification penetration criterion for N95FFR. 
penetration valued ranged from $0.95 \%$ to $5.83 \%$. The standard deviations ranged from $0.02 \%$ to $1.95 \%$ and $0.02 \%$ to $1.97 \%$ for initial and maximum penetration, respectively. Of the $21 \mathrm{NIOSH}-$ certified $\mathrm{N} 95$ respirator models tested in this study, 19 models had both average initial and maximum penetration results measured with the TSI 8130 AFT of less than $5 \% .{ }^{21}$ The maximum penetration level allowed by NIOSH for N95 certification using the 42 CFR 84 test requirement is $5 \%$. The Gerson Model 2737 (Louis M. Gerson, Middleboro, MA) and Magid Model KR795 (Magid Glove and Safety Manufacturing, Chicago, IL) each had 2 of 3 samples that did not pass the NIOSH certification requirement using the filter test method used here. However, for each of these 2 models, the means of the initial and maximum penetrations are only slightly higher than $5 \%$ (Gerson: both mean initial and mean maximum penetration $=5.83 \%$; Magid: mean initial penetration $=$ $5.44 \%$ and mean maximum penetration $=5.59 \%$ ). Mean filter resistance at maximum penetration was also obtained. All of the filter resistance levels measured using the AFTwere within the NIOSH certification requirements of $\leq 35 \mathrm{~mm}$ water column height pressure $\left(\mathrm{mm} \mathrm{H}_{2} \mathrm{O}\right) .{ }^{21}$ Values ranged from a low of $7.40 \mathrm{~mm} \mathrm{H}_{2} \mathrm{O}$ (Survivair Model 1930; Sperian Respiratory Protection, Santa Clara, CA) to $30.07 \mathrm{~mm} \mathrm{H}_{2} \mathrm{O}$ (Willson Model 1410N95; Willson Dalloz Safety Products, Santa Clara, CA).

\section{DISCUSSION}

Nineteen of the 21 models had initial penetration levels less than $5 \%$. The filtration test used in this investigation, similar to the NIOSH certification test, is performed under a "worst-case" set of conditions (eg, high flow rate, charge neutralized particles). That said, the 2 models of N95FFRs (Gerson Model 2737 and Magid Model KR795) that failed the test by less than $1 \%$ are still likely to achieve good filtration performance against common workplace aerosols, similar to previous results reported on degraded electret filter media. ${ }^{7,15}$

There did not appear to be any relationship between the length of storage and failure to pass the initial penetration test. One of the products (Gerson 2737) with an average penetration level greater than $5 \%$ was stored $\sim 10$ years, whereas the other product (Magid KR795) was stored $\sim 6$ years. The only other respirator model stored $\sim 10$ years (Survivair 1930 ) had very good filtration performance $(1.41 \%)$ for both initial and maximum penetration. The 2 products with lowest mean maximum penetration values were 3M $8512(0.98 \%)$ and Willson N9510M (0.95\%); both had been stored $\sim 7$ years. Considering that (1) all N95FFRs were stored in their original packaging and within cardboard boxes used for shipment and (2) all N95FFRs experienced similar environmental storage conditions (temperature and humidity levels), the degree of filtration efficiency degradation is likely model specific.

It is also interesting to compare the results for initial and maximum penetration. As shown in Table 2, the average initial penetration values are identical to the average maximum penetration for 8 of 21 respirators (38\%). Furthermore, the average maximum penetration was $10 \%$ greater than average initial penetration in only 6 cases $(28.6 \%)$. Thus, initial penetration can be used to assess the status of stored respirators, without resorting to the more complicated and time intensive (90-100 minutes) maximum penetration test, which requires loading the respirator with $200 \mathrm{mg}$ sodium chloride aerosol.

This investigation was not designed to be a typical aging study; hence, true "before-and-after" comparisons are not presented. The length of time each respirator was stored varied between 6 and 10 years. The average length of storage was 7.3 years for the 21 models in this study. No data are available on the initial or maximum penetration for these products at the time they were purchased. Because all were NIOSH-certified respirators, the authors assumed that all of the products passed NIOSH performance criteria when they were purchased. This was a sample of "convenience"; as such, the authors decided to take advantage of the fact that these stored respirators may offer some useful information to stockpile administrators about the potential longevity of N95FFRs until there is an opportunity to conduct a more formal aging investigation. Thus, it was not possible to do a true "before-and-after" analysis (eg, using a paired $t$ test) to ascertain any statistically significant changes in filtration efficiency. This is a limitation of the study. Further research is needed to understand better the mechanisms and storage conditions that cause filtration efficiency degradation over prolonged storage periods.

Another limitation of the study is the fact that only 21 randomly selected respirator models were analyzed, and this only represents a small subset of the more than 300 commercially available NIOSH-certified N95FFRs. Those N95FFRs not evaluated in this study may include respirators that would have tested worse than or superior to all or any of the ones that were evaluated. Additionally, respirator manufacturers are continually changing, improving, and redesigning their products to continue to meet NIOSH certification performance standards while, at times, keeping the same model numbers. It must be noted that 42 CFR 84 requires all changes and modifications to respirators be examined by NIOSH to determine whether testing is required (42 CFR 84.35). Furthermore, if necessary, NIOSH will retest any modification that can affect performance. ${ }^{21}$ Therefore, the N95FFRs analyzed in this study may or may not be representative of models currently on the market today. 
Although results from this study show that nearly all (19 of 21 models [90.5\%]) maintained filtration efficiency below $5 \%$, respirator stockpile administrators should consider contacting respirator manufacturers to inquire whether specific storage time limitations are recommended for their products. Administrators should also consider periodic (perhaps annual) evaluation (eg, obtain initial penetration data) of representative samples from their stockpile to ensure that their N95FFRs maintain expected filtration efficiencies after several years of storage. It should also be noted that only filter penetration and filter resistance were measured in this study and that other considerations, such as conditions of straps or strap attachments, may affect the successful fit and use of an N95FFR.

\section{CONCLUSION}

Overall, results from this study indicate that most N95FFRs stored for up to 10 years in warehouse and laboratory conditions, similar to those of this study, will likely maintain their filtration performance following storage. Of the 21 N95 respirator models tested, only 2 models had mean initial and mean maximum penetration results slightly greater $(<1 \%)$ above the NIOSH certification criterion of $\leq 5 \%$ for N95 class filters. Considering that all N95FFRs were stored in their original packaging and experienced similar environmental storage conditions, with only the exception of storage duration, observations of penetration values above $5 \%$ were likely model specific.

The authors thank Dr. William P. King, Dr. Raymond Roberge, Jay Parker, William Newcomb, and Dr. Samy Rengasamy of the National Institute for Occupational Safety and Health/National Personal Protective Technology Laboratory and R. Brent Lawrence of the National Institute for Occupational Safety and Health/ Division of Respiratory Disease Studies for their insightful critical reviews, suggestions, and contributions and Larry Janssen from 3M and Dr. Jeffrey Birkner from Moldex for their knowledgeable reviews from the viewpoint of a manufacturer.

\section{References}

I. Institute of Medicine (US). Reusability of facemasks during an influenza pandemic. Washington: The Institute; 2006.

2. Rubinson L, Nuzzo JB, Talmor DS. Augmentation of hospital critical care capacity after bioterrorist attacks or epidemics: recommendations of the Working Group on Emergency Mass Critical Care. Crit Care Med 2005;33(Suppl):E2393.

3. Schmit J. Disposable respirator demand on rise. USA TODAY 2006 August 17. Available at: http://www.usatoday.com/money/industries/ health/2006-08-I7-n95-masks-usat_x.htm. Accessed May 14, 2008.
4. Roberge R. Effect of surgical masks worn concurrently over N95 filtering facepiece respirators: extended service life versus increased user burden. J Pub Health Manage 2008; 14:EI9-26.

5. Hinds WC. Aerosol technology: properties, behavior, and measurements of airborne particles. 2nd ed. New York: Wiley; 1998. p. 196.

6. Barrett LW, Rousseau AD. Aerosol loading performance of electret filter media. Am Indust Hyg Assoc J 1998;59(8):532-9.

7. Janssen LL, Bidwell JO. Mullins, HE, Nelson TJ. Efficiency of degraded electret filters: part II. Field testing against workplace aerosols. J Int Soc Resp Protect 2003;20(2):81-90.

8. Martin SB, Moyer E. Electrostatic respirator filter media: filter efficiency and most penetrating particle size effects. Appl Occup Environ Hyg 2000;15:609-17.

9. Jasper W, Hinestroza J, Mohan A, Thompson D, Barker R. Effect of phase of toluene on filtration performance of electret filter media against di-octyl-phthalate aerosols. J Int Soc Resp Protect 2005;22: 97-105.

10. Jasper W, Hinestroza J, Mohan A, Kim J, Shiels B, Gunay M, et al. Effect of xylene exposure on the performance of electret filter media. J Aerosol Sci 2006;37:903-II.

II. Viscusi DJ, King WP, Shaffer RE. Effect of decontamination on the filtration efficiency of two filtering facepiece respirator models. J Int Soc Resp Protect 2007;24:93-107.

12. Moyer ES, Bergman MS. Electrostatic N-95 respirator filter media efficiency degradation resulting from intermittent sodium chloride aerosol exposure. Appl Occup Environ Hyg 2000; 15:600-8.

13. Kanaoka C, Emi H, Ishiguro T. Time dependency of collection performance of electret filter. In: Liu BYH, Pui DYH, Fissan HJ, editors. New York: Elsevier; p. 613-616.

14. Walsh DC, Stenhouse JIT. Parameters affecting the loading behavior and degradation of electrically active filter materials. Aerosol Sci Tech 1998;29(5):419-32.

15. Janssen LL, Bidwell JO, Mullins HE, Nelson TJ. Efficiency of degraded electret filters: part I. Laboratory testing against $\mathrm{NaCl}$ and DOP before and after exposure to workplace aerosols. J Int Soc Resp Protect 2003;20(2):7I-80.

16. Ackley MW. Degradation of electrostatic filters at elevated temperature and humidity. Filtration Separation 1982;22:239-42.

17. Van Turnhout J. Electret split fibers for high-efficiency filtration of polluted air. Proceedings of the First International Symposium On Electrets and Dialectics. Brazil: Sao Carlos; 1975. p. 87-96.

18. Van Turnhout J, Van Bochave C, Van Veldhulzen GJ. Electret fibers for high-efficiency filtration of polluted gases. Staub-Reinhart der Luft 1976;36:36-9.

19. Motyl E, Lowkis B. Effect of air humidity on charge decay and lifetime of PP electret nonwovens. Fibres \& Textiles in Eastern Europe 2006; 14:39-42.

20. Respiratory protection. 29 C.F.R. §1910.134. 1998. Available at: http:// frwebgate.access.gpo.gov/cgi-bin/get-cfr.cgi. Accessed December 08, 2008.

21. Approval of respiratory protective devices. 42 C.F.R. $\$ 84.180$ \& 84.181. 1995. Available at: http://www.access.gpo.gov/nara/cfr/waisidx_ 04/42cfr84_04.html. Accessed December 08, 2008.

22. Johnson T, Smith $\mathrm{S}$. Correlation of penetration results between filter testers that use different particle generators and detection methods. Proceedings of the 1998 Nonwovens Conference. March 9-II, 1998. St. Petersburg: FL. TAPPI; 1998.

23. National Institute for Occupational Safety and Health (NIOSH). Procedure No. RCT-APR-STP-0057, 0058, 0059, Rev. I.I. DHHS, Centers for Disease Control and Prevention; 2005. Available at: http://www. cdc.gov/niosh/nppt//stps/respirator_testing.htm. Accessed December 08, 2008. 